\title{
Granulation Behavior of an Iron Ore Sintering Mixture Containing High Grade Pellet Feed with Different Specific Surface
}

\author{
Vinícius de Morais OLIVEIRA, ${ }^{1) *}$ Alei Leite Alcantara DOMINGUES, ${ }^{1)}$ Mauricio Covcevich BAGATINI ${ }^{2)}$ and \\ Valdirene Gonzaga de RESENDE ${ }^{1)}$ \\ 1) Ferrous Technology Center, Vale S.A., Nova Lima, MG, Brazil. \\ 2) Metallurgical Department, Federal University of Minas Gerais (UFMG), Belo Horizonte, MG, Brazil.
}

(Received on March 10, 2020; accepted on July 1, 2020)

\begin{abstract}
High-grade iron ores became more attractive due to the searching for lower slag rate operation in blast furnaces aiming to reduce $\mathrm{CO}_{2}$ emissions as the environmental regulation became even more restricted. The granulation behavior of high-grade ores individually and together with other iron ores played an important role for sintering process. In this context, this work aims to evaluate the granulation behavior of a pellet feed with different specific surfaces. To carry out this study, $25 \%$ of pellet feed was added to an iron ore mix in a bench scale drum. The Granulation Index (GI) was determined and samples were collected after granulation step for quasi-particles investigation. The results showed that a previous mechanical treatment of the pellet feed by roller press is suitable in order to enable a good granulation behavior of this fine material, which was essential to guarantee its use as raw material in sintering process. The fraction below $0.045 \mathrm{~mm}$ of the pressed pellet feed helped to improve the granulation of the natural pellet feed. The thickness of the adherent layer and means size of quasi-particles increased with the specific surface. The Gl results increase with the pellet feed specific surface, up to $1400-1500 \mathrm{~cm}^{2} / \mathrm{g}$ stabilizing around $86-90 \%$. The fines below $0.15 \mathrm{~mm}$ that remained agglomerated, after drop test, had similar behavior of Gl. Finally, it was possible to obtain a minimum specific surface level $\left(1400-1500 \mathrm{~cm}^{2} / \mathrm{g}\right)$ to achieve an optimum performance in the granulation step which may promote a good sintering process permeability conditions.
\end{abstract}

KEY WORDS: iron ore; granulation; pellet feed; roller press; specific surface.

\section{Introduction}

One important step of the iron ore sintering process is the raw materials preparation, which means that these materials need to be mixed and subsequently granulated. Recently, due to the increase of fine portion of the sinter feeds and also the availability of concentrates, such as pellet feeds, this step played an important role to guarantee good permeability conditions for sintering process. ${ }^{1,2)}$

Granulation is the term used to name the process of increasing particle size to a certain optimal size with spherical shape by using fine and very fine particles. According to Walker $^{3)}$ the granulation happens when a bed of solid particles moves with simultaneous intensive mixing in the presence of a liquid phase. This movement provides particle collisions and individual particles coalesce. Further granule growth takes place by layering on to this nuclei. The granulation is considered a physical phenomenon, involving physical interactions mainly due to capillary forces.

\footnotetext{
* Corresponding author: E-mail: vinicius.morais@vale.com
}

The iron ore sintering can be divided in two important steps which are the granulation and the thermal densification, which determine the final quality of the sinter as well the sintering process performance. ${ }^{4)}$ The characteristics of iron ore affect the sintering process, because it impact on these two steps of the process. Vieira et al. ${ }^{5)}$ mentioned that many studies in the literature have discussed the importance and the relationship between the microstructural characteristics of the ore fines and the efficiency of the cold agglomeration stage in the sintering process and the final quality of the sinter. Kohsa and Manuel ${ }^{6}$ ) highlighted that the granulation is needed to improve the bed permeability in sintering process.

Ishikawa et al. ${ }^{7)}$ and Satoh $^{8)}$ described an investigation about the granulation process, disclosing the studies about the concept of pseudo-particles or quasi-particles formed by nucleus and adherent fines. They introduced a method to quantify the iron ore mixture behavior, which is the Granulation Index (GI). The authors proposed that particles larger than $1.00 \mathrm{~mm}$ act as nuclei, particles less than $0.20 \mathrm{~mm}$ act as adhesive powder and particles between $0.20 \mathrm{~mm}$ and 1.00 
mm work as intermediate particles during the granulation process. Other authors also mentioned similar classification of iron ore particles and its importance to better understanding of the granulation behavior of iron ores. ${ }^{4,9,10)}$ For the same type of ore, the increase of the quantity of adhesive powder improves the morphology of the granules and their size distribution becomes narrower, but with a smaller average size. ${ }^{4)}$ However, this improvement is not translated into an increase in permeability the bed as a whole. Umadevi et al. ${ }^{11)}$ reported that finer fraction i.e. $-0.15 \mathrm{~mm}$ increases with the decrease in iron ore mean particle size and a large quantity of finer particle in the sinter mix decreases the granulation efficiency and reduces the Flame Front Speed (FFS). It is a consensus in the literature that the permeability of the ore mixture to be sintered decreases as the amount of fines increases.

Other physical characteristics such as porosity, shape and particle surface characteristics also affect granulation performance. The forces that bind the ultrafines to larger particles are due to the capillarity effect by the presence of water, so the iteration between water and ore particles is very important. Zhu et al. ${ }^{12)}$ described the concentrates and pellet feeds as raw materials for pelletizing process and mentioned the need of the roller press treatment to improve its use. Abzavapor et al. ${ }^{13)}$ mentioned the benefits of using roller press in terms of the shape of the particles to produce pellets. Other authors investigated the use of concentrates and pellet feed, which were previously pre-treated in roller press aiming to increase its specific surface, in sintering process showing that the pre-treatment allows to use these materials without losing process permeability. ${ }^{14-16)}$ Those findings were recently reinforced by Yang et al. ${ }^{2)}$ who investigated different size distribution of specular hematite ore types and Oliveira et al. ${ }^{17)}$ whom reported that it was also possible to replace coarse sinter feeds without losing productivity.

Finally, the present work aims to evaluate the granulation behavior of pellet feed together with other iron ores. The pellet feed was used as it was produced in mining (from here on called natural), treated in a roller press and prepared from the fraction below $0.045 \mathrm{~mm}$. The iron ore mixtures were evaluated in a small drum which was designed to reproduce the granulation behavior of the mix, with one step for mixing and another for granulation at fixed process conditions (rotation, drum speed, time and loading conditions). For this evaluation, $25 \%$ of pellet feed was added to the mix. The GI was determined and samples were collected after granulating step for quasi-particles evaluation by optical microscopy. Additionally, drop test were carried out to determine the strength of the quasi-particles formed.

\section{Experimental Procedure}

\subsection{The Pellet Feed and Iron Ore Mixtures}

A Brazilian pellet feed natural and after mechanical treatment by roller press (LABWAL model, manufactured by Polysius AG) was used in this work. The pellet feed passed through roller press to achieve a high specific surface. The pressing parameters were $8 \times 10^{6} \mathrm{~Pa}$ of pressure and $8 \%$ of moisture. The natural and pressed pellet feed were submitted to a screening process and samples of both materials with size below $0.045 \mathrm{~mm}$ were collected. The samples were codenamed as PF A for the natural pellet feed, PF A.1 for the fraction below $0.045 \mathrm{~mm}$ of the natural sample, PF B for the pellet feed after roller press, and finally PF B.1 for the fraction under $0.045 \mathrm{~mm}$ of sample PF B.

The specific surface of the samples was determined using a ZEB PC Blaine equipment (Zunderwerke model) and by nitrogen adsorption method (B.E.T. method), using Quantachrome equipment (NOVA 1000e model). Additionally, the ballability index $(\mathrm{K})$ of the pellet feeds was determined using an apparatus specially manufactured for such analysis and based on the method mainly used and developed in China ${ }^{15)}$ which is based on water retention capacity and the maximum capillarity forces of the iron ore sample. The ballability index $(\mathrm{K})$ is used to evaluate how easy iron ores can be pelletized, based in the interaction with water, which can be calculated from the following Eq. (1):

$$
K=\frac{W h}{(W c-W h)}
$$

where: $\mathrm{K}$ is the ballability index

Wh is the water holding

Wc is the capilar water

Scanning Electron Microscopy (SEM) images of the pellet feed particles were collected using a Carl Zeiss ${ }^{\circledR}$ microscope, EVO MA15 model.

Sinter feeds from Australia and Brazil were used in this work. Table 1 shows the iron ore mixture tested. The pellet feed level was fixed in $25 \%$ of the total mixture. The natural and pressed pellet feeds (PFA and PFB respectively) and its fraction below $0.045 \mathrm{~mm}$ (PFA.1 and PFB.1) were tested individually.

Additionally, the fractions below $0.045 \mathrm{~mm}$ were mixed with the regular pellet feeds (natural and prepared in roller press) in different proportions ratio $9 \% / 16 \%$ and $16 \% / 9 \%$ maintaining the total ratio of pellet feed in the iron ore mixture of $25 \%$. This investigation aims to evaluate if the incorporation of the fractions below $0.045 \mathrm{~mm}$ could be effective to improve the granulation behavior of the iron ore mix containing more ultrafine particles and also to evaluate the effect of the average specific surface of the pellet feed on the granulation behavior of the iron ore mixture.

For a complete chemical and mineralogical characterization of the pellet feed, sinter feeds, as well as of the raw materials used in the present work, the reader is referred to the work of Oliveira et al. ${ }^{17)}$

\subsection{Granulation Tests}

The iron ore mixtures were granulated in a bench scale drum, according to the conditions listed in Table 2. The procedure stablished for this test was based on the methodology reported in literature ${ }^{7,8)}$ and recently studied by

Table 1. Iron ore mixtures tested.

\begin{tabular}{cc}
\hline Iron ores & Participation \\
\hline Australian sinter feeds, \% & 40 \\
Brazilian sinter feeds, \% & 35 \\
Pellet Feeds, \% & 25 \\
\hline
\end{tabular}


different authors. ${ }^{18-21)}$

After mixing and granulating, according to the conditions listed in Table 2, the agglomerated particles were transferred to a carrousel divider and splitted in four aliquots of approximately $400 \mathrm{~g}$ each. The samples were divided as following: two for granulation test, one for microscopy analysis and another for moisture determination.

The portion for the granulation test was screened in sieve sizes of $4.76 \mathrm{~mm}, 2.00 \mathrm{~mm}, 1.00 \mathrm{~mm}, 0.50 \mathrm{~mm}$ and 0.25 $\mathrm{mm}$. Subsequently, it passes through disaggregation process to determine the amount of particles smaller than $0.25 \mathrm{~mm}$ which were adhering to agglomerates larger than $0.25 \mathrm{~mm}$. To infer the granulation performance, the GI was calculated from the Eq. (2) below:

$$
G I(\%)=\frac{(a-b)}{a} \times 100
$$

where:

a: the amount of particles smaller than $0.25 \mathrm{~mm}$ agglomerated plus the no agglomerated particles, reported in grams. $\mathrm{b}$ : the amount of particles with less than $0.25 \mathrm{~mm}$ no

Table 2. Experimental procedure for mixing and granulating.

\begin{tabular}{ccc}
\hline Drum characteristics & Step & Parameters \\
\hline Volume: $0.125 \mathrm{~m}^{3}$ & & Time: $120 \mathrm{~s}$ \\
& Mixing & $\begin{array}{c}\text { Rotation speed: } \\
18 \text { RPM }\end{array}$ \\
\cline { 2 - 3 } Length: $0.250 \mathrm{~m}$ & & Time: $360 \mathrm{~s}$ \\
& & Rotation speed: \\
Diameter: $0.240 \mathrm{~m}$ & Granulation & 18 RPM \\
& & Water addition: \\
Typical samples weight: 2400 grams & & $100 \%$ \\
\hline
\end{tabular}

agglomerated, reported in grams.

The test was performed twice and the final value of GI represents the average of these two tests. If the difference between the results were higher than $3 \%$, the test was repeated. Additionally, the particle size distribution of the agglomerated particles (mean size) was also determined.

\subsection{Quasi-particles Evaluation}

For a better understanding of the phenomena involved during the granulation step the quasi-particles (agglomerated particles) were analyzed by optical microscopy through an automatic methodology ${ }^{22}$ specially developed for such characterization type and drop test.

The samples of agglomerated particles were classified in the following size ranges: $>4.76 \mathrm{~mm},>2.83 \mathrm{~mm}$ and $<$ $4.76 \mathrm{~mm}$, and $>1.00 \mathrm{~mm}$ and $<2.83 \mathrm{~mm}$, Fig. 1(a). Figure 1(b) shows the agglomerated particles in a polished section. Figure 1(c) shows detailed images of the types of agglomerated particles obtained by optical microscopy and their classification into quasi-particles (nucleus particles surrounded by adherent fines), micropellets (composed by adherent fine particles agglomerated) and non-agglomerated particles. The quasi-particles were described initially by Ishikawa et $a l$. and Satoh ${ }^{5,6)}$ and later studied by several authors. The micropellet particles became more important recently due to the increase of fine particles below $0.15 \mathrm{~mm}$ as a result of the incorporation of pellet feed or concentrates into the iron ore mixtures as reported by different authors. ${ }^{14-17,20,21)}$

The samples were analyzed by optical microscopy, using a Carl Zeiss ${ }^{\circledR}$ microscope, AxioImager Z2m model. An image analyzer software was used and the agglomerated particles (quasi-particles, micropellets, non-agglomerated particles) were quantified in different types by dot counting. The nucleus type particles and the thickness of the adherent

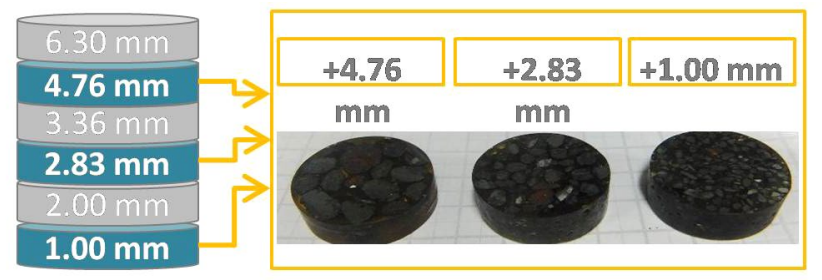

(a)

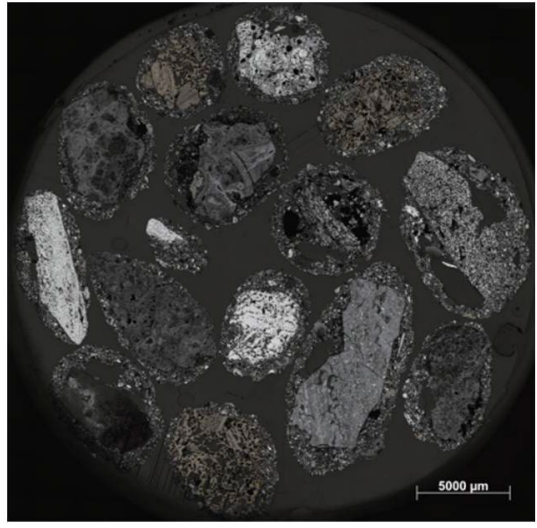

(b)

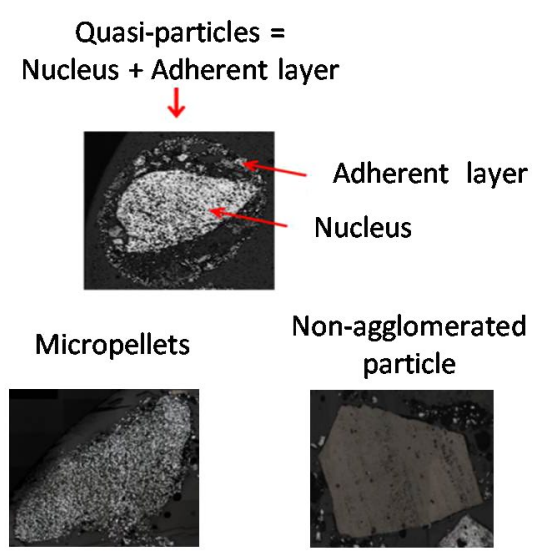

(c)

Fig. 1. (a) Sample preparation at different particles sizes; (b) agglomerated particles in a polished section; and (c) details of particles classification. (Online version in color.) 
layer were also quantified. The automatic analysis procedure developed was recently published. ${ }^{22)}$

The quasi-particles drop test was carried out following a procedure based on the standard JIS M 8711 used for Shatter Index determination of sinter product. In this test, the amount of fines below $0.15 \mathrm{~mm}$ was measured before and after 2 drops. These results were compared with the amount of fines below $0.15 \mathrm{~mm}$ of the iron ore mixture before drum mixing. Finally, an estimative of the amount of fines that were still joined to the nucleus particles was determined.

\section{Results and Discussion}

\subsection{Pellet Feed Characterization}

Figure 2 shows the size distribution of the pellet feed samples used in this work. As expected, the fractions below $0.045 \mathrm{~mm}$ of the pellets, PF A.1 and PF B.1, are finer than the pellet feeds PF A and PF B.

Figures 3(a) and 3(b) shows SEM images of the fractions below $0.045 \mathrm{~mm}$ of the natural pellet feed and after pressing (samples A.1 and B.1, respectively). The PF B.1 sample contains much more ultrafine particles as compared to PF A.1 and the large particles were surrounded by those ultrafine. Additionally, the large particles became rare being

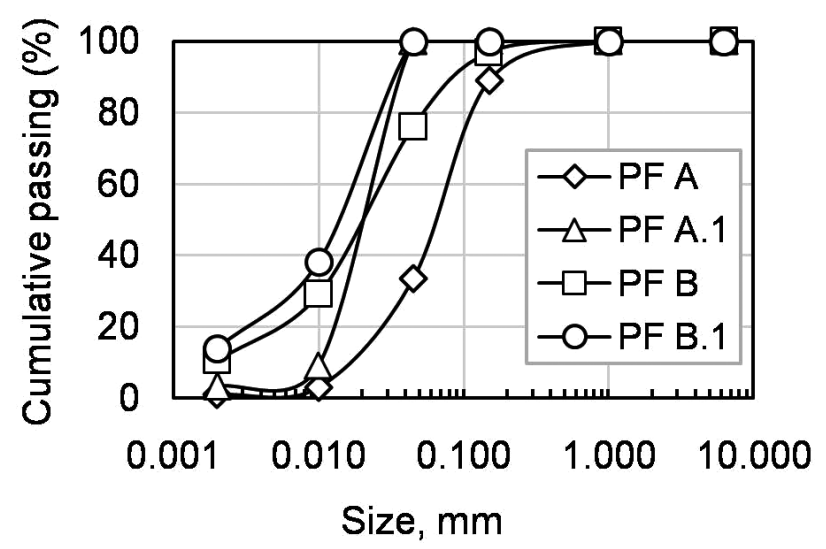

Fig. 2. Size distribution of the pellet feed samples.

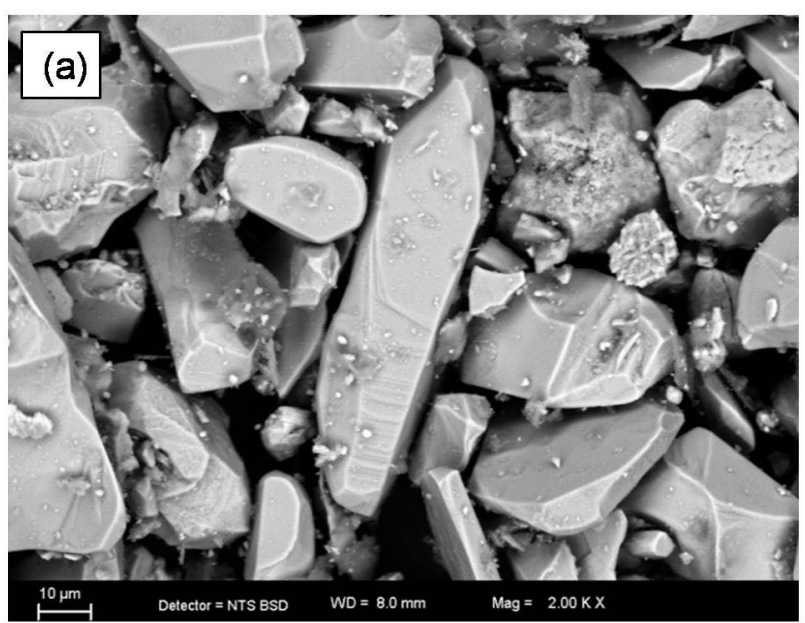

replaced by smaller particles and some cracks (Figs. 3(a) and 3(b)). Both effects were due to the action of the roller press as reported in literature. ${ }^{12,13)}$

Table 3 shows the results of specific surface of the samples using different techniques, one based on air permeability test (Blaine Index) and another one based on nitrogen adsorption method (B.E.T.). It can be observed that the fraction below $0.045 \mathrm{~mm}$ of the pressed pellet feed presents the highest specific surface area through both techniques, similar results were reported in literature. ${ }^{17,23)}$ Concerning the ballability index $(\mathrm{K})$, it increases as the specific surface of the pellet feed increases, reaching values over 0.6 , which is considered a good level of $\mathrm{K}$ factor for a good agglomeration behavior according to Jian et al. ${ }^{15)}$

\subsection{Granulation Test Results}

The granulation test was performed at fixed moisture level of $7.5 \%$. Tests were performed with moisture level higher than $7.5 \%$, but it was not practical due to the impact on the homogenization of the iron ore mixture causing problems in the reproducibility of the test. Table $\mathbf{4}$ shows more details of the iron ore mixture tested in the present work. The level of particles lower than $0.010 \mathrm{~mm}$ of the iron ore mixture increases with the increase of the specific surface of the pellet feeds.

The aimed chemical quality of the sinter $\left(\mathrm{Fe}: 57.5 \%, \mathrm{SiO}_{2}\right.$ : 5.70\%; $\mathrm{Al}_{2} \mathrm{O}_{3}: 1.40 \%$; P: $0.044 \%$; and ratio $\% \mathrm{CaO} / \% \mathrm{SiO}_{2}$ : 1.60 ) is based on a typical Asian blast furnace operation (high level of sinter product in ferrous burden) to guarantee a optimum permeability, good metallurgical performance and low slag rate.

Table 5 shows the results of GI and agglomerated par-

Table 3. Specific surface and ballability index of pellet feeds.

\begin{tabular}{cccc}
\hline Pellet Feed & Blaine Index $\left(\mathrm{cm}^{2} / \mathrm{g}\right)$ & B.E.T. $\left(\mathrm{m}^{2} / \mathrm{g}\right)$ & Ballability, K \\
\hline PF A & 433 & 0.80 & 0.17 \\
PF B & 1468 & 1.70 & 0.58 \\
PF A.1 & 750 & 1.44 & 0.20 \\
PF B.1 & 2100 & 2.13 & 0.80 \\
\hline
\end{tabular}

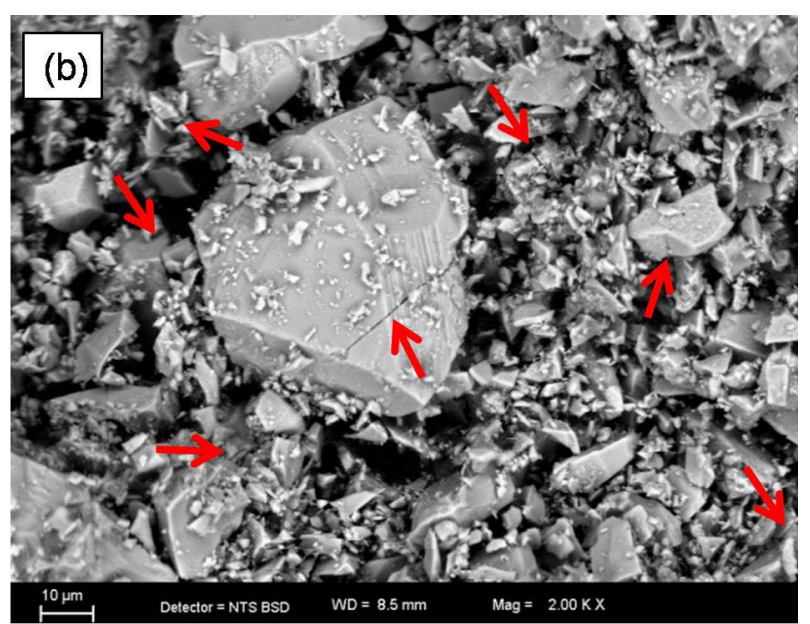

Fig. 3. SEM images: (a) PF A.1, fraction below $0.045 \mathrm{~mm}$ of the natural pellet feed (PFA); and PF B.1, fraction below $0.045 \mathrm{~mm}$ of the pressed pellet feed (PF B). The arrows indicate cracks on the surface of the particles. (Online version in color.) 
Table 4. Details of iron ore mixtures tested.

\begin{tabular}{|c|c|c|c|c|}
\hline Parameter & Case PF A & Case PF A.1 & Case PF B & Case PF B.1 \\
\hline \multicolumn{5}{|c|}{ Iron ore mixture } \\
\hline Sinter feeds & 75 & 75 & 75 & 75 \\
\hline $\begin{array}{c}\text { Pellet feed, PF } \\
\text { A }\end{array}$ & 25 & 0 & 0 & 0 \\
\hline $\begin{array}{l}\text { Pellet feed, PF } \\
\text { A.1 }\end{array}$ & 0 & 25 & 0 & 0 \\
\hline $\begin{array}{l}\text { Pellet feed, PF } \\
\text { B }\end{array}$ & 0 & 0 & 25 & 0 \\
\hline $\begin{array}{l}\text { Pellet feed, PF } \\
\text { B.1 }\end{array}$ & 0 & 0 & 0 & 25 \\
\hline $\begin{array}{c}\text { Pellet feed } \\
\text { Specific } \\
\text { Surface }^{*}, \mathrm{~cm}^{2} / \mathrm{g}\end{array}$ & 430 & 750 & 1468 & 2100 \\
\hline \multicolumn{5}{|c|}{ Granulometric distribution of iron ore mixtures } \\
\hline$+1.000 \mathrm{~mm}, \%$ & 39.3 & 39.3 & 39.3 & 39.3 \\
\hline$-0.150 \mathrm{~mm}, \%$ & 41.7 & 44.4 & 43.6 & 44.4 \\
\hline$-0.045 \mathrm{~mm}, \%$ & 21.3 & 38.0 & 32.0 & 38.0 \\
\hline$-0.010 \mathrm{~mm}, \%$ & 9.7 & 11.3 & 16.2 & 18.5 \\
\hline \multicolumn{5}{|c|}{ Fluxes and additives } \\
\hline Coke Breeze, $\%$ & \multicolumn{4}{|c|}{4.0} \\
\hline Burnt lime, $\%$ & \multicolumn{4}{|c|}{3.0} \\
\hline $\begin{array}{c}\text { Fluxes total, } \\
\mathrm{Kg} / \mathrm{t}\end{array}$ & \multicolumn{4}{|c|}{126} \\
\hline
\end{tabular}

* Blaine Index

Table 5. Results of GI and agglomerated particles mean size for the iron ore mixtures.

\begin{tabular}{ccc}
\hline Case & GI, \% & $\begin{array}{c}\text { Mean size of agglomerated } \\
\text { particles, mm }\end{array}$ \\
\hline Case PF A & 76.3 & 2.25 \\
Case PF A.1 & 78.2 & 2.82 \\
Case PF B & 89.5 & 2.91 \\
Case PF B.1 & 88.9 & 3.35 \\
\hline
\end{tabular}

ticles mean size for the iron ore mixtures containing pellet feed and its fraction below $0.045 \mathrm{~mm}$. The pressed pellet feed, PF B, and its fraction below $0.045 \mathrm{~mm}$, PF B.1, presented better GI and mean size of agglomerated particles results than natural pellet feed, $\mathrm{PF} \mathrm{A}$, and its fraction below $0.045 \mathrm{~mm}$, PF A.1. Comparing the pellet feeds with its fraction below $0.045 \mathrm{~mm}$ similar results were achieved. The mean size of agglomerated particles increased with the increase of specific surface of the pellet feeds and with the fraction below $0.010 \mathrm{~mm}$ of the average iron ore mixture.

Figure 4 shows the results of GI when the fractions below $0.045 \mathrm{~mm}$ of the pellet feeds were mixed with natural pellet feed in different proportions as described previously. The fraction below $0.045 \mathrm{~mm}$ of the pressed pellet feed (PF B.1) improved the granulation behavior of the natural pellet feed, whereas the granulation decreased when the fraction below $0.045 \mathrm{~mm}$ of natural pellet feed (PF A.1) was mixed with natural pellet feed. These results showed that the fraction below $0.045 \mathrm{~mm}$ of the PF B.1 is different, indicating

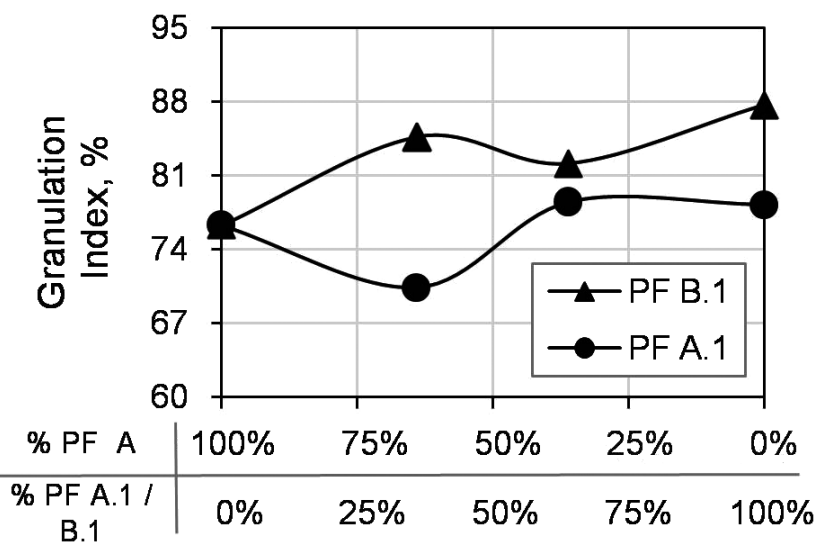

Fig. 4. GI results obtained when the fraction below $0.045 \mathrm{~mm}$ (samples PF A.1 and PF B.1) was mixed with natural pellet feed (PF A).

Table 6. Average specific surface of the mixtures of pellet feeds.

\begin{tabular}{ccccc}
\hline$\%$ PF A & $\%$ PF B & $\%$ PF A.1 & $\%$ PF B.1 & $\begin{array}{c}\text { Average specific surface } \\
\left(\mathrm{cm}^{2} / \mathrm{g}\right)\end{array}$ \\
\hline 25 & - & - & - & 430 \\
- & - & 25 & - & 750 \\
- & 25 & - & - & 1470 \\
16 & - & - & 25 & 2100 \\
9 & - & 9 & - & 545 \\
- & 9 & 16 & - & 635 \\
16 & - & - & 9 & 1000 \\
12 & - & - & 13 & 1031 \\
9 & - & - & 16 & 1300 \\
- & 16 & - & 9 & 1699 \\
- & 9 & - & 16 & 1897 \\
\hline
\end{tabular}

that the roller press treatment contribute to guarantee a good cold agglomeration granulation performance of this material.

The Table 6 shows the average specific surface of the cases where the fractions below $0.045 \mathrm{~mm}$ were mixed with the regular pellet feeds (natural and prepared in roller press) in different proportions maintaining the total pellet feed ratio in the iron ore mixture in $25 \%$.

Figures 5(a) and 5(b) show GI results and mean size of agglomerated particles after granulation test as a function of the average pellet feed specific surface (Blaine Index). It is possible to note an increase of GI with the specific surface up to $1400-1500 \mathrm{~cm}^{2} / \mathrm{g}$. For specific surface higher than this value a stabilization of GI around $86-90 \%$ was observed. Concerning the mean size of the agglomerated particles formed after the granulation step, it is observed a trend to increase with the increase of specific surface, Fig. 5(b). These results were not in line with GI results as mentioned previously, which may be explained by a low strength of the agglomerated particles. To better understand these results, the investigation of the quasi-particles formed during the granulation behavior is of paramount importance. 


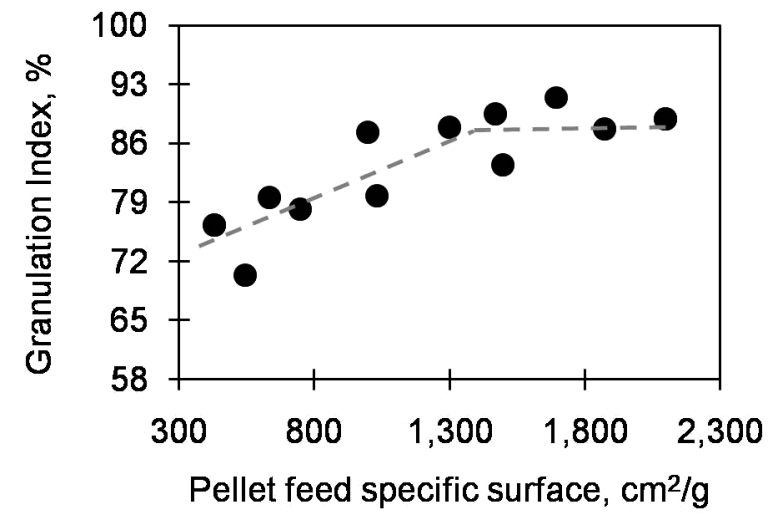

(a)

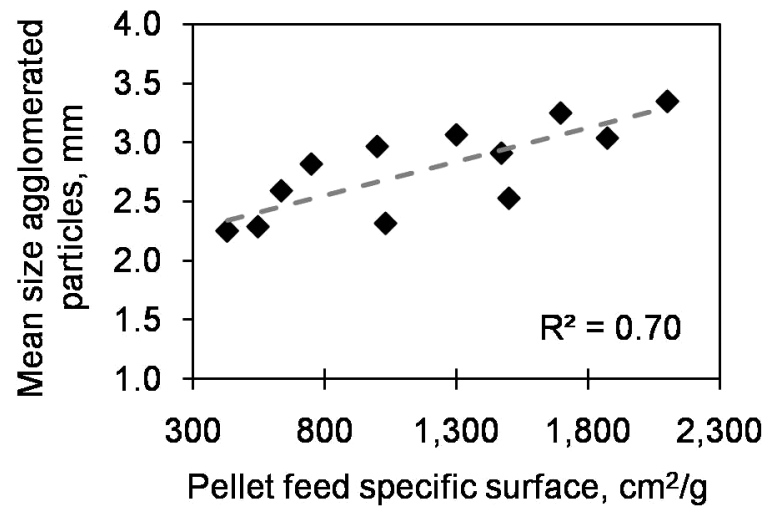

(b)

Fig. 5. (a) GI results and specific surface of the pellet feeds; and (b) mean size of agglomerated particles after granulation test and specific surface of the pellet feeds

\subsection{Microscopy Analysis and Drop Test Results}

The quasi-particle evaluation by optical microscopy was done aiming to better understand the cold agglomeration phenomena involved during granulation step and also investigate the hypothesis previously raised.

Table 7 shows a summary of the main results obtained by optical microscopy analysis. About thickness of adherent layer, an increasing trend with specific surface was observed. The growing of the adherent layer due to the deposition of ultrafines seems to be the mechanism of growing phenomena (layering), as other authors recently reported in literature. ${ }^{20)}$ No clear correlation was observed with circularity.

In terms of particle type formed, a downward trend of non-agglomerated particles was observed with the increase of specific surface. No clear correlation was observed between quasi-particles nether micropellets formed. Finally, the type of nucleus particles did not show a clear trend when the specific surface was varied.

Figures 6, 7 and 8 shows the correlation between the optical microscopy results of the quasi-particles with the specific surface of the pellet feed.

Figure 6(a) shows that the thickness of the adherent layer increases with the specific surface. This result was in line with the increase of the mean size of agglomerated particles obtained in granulation test. Additional tests were required to better understand this behavior. On the other hand, the circularity of agglomerated particles did not demonstrate any correlation (Fig. 6(b)), confirming the results of individual tests (Table 7 ).

Figures 7(a), 7(b) and 7(c) show the particle type formed during the granulation process for the different specific surfaces of pellet feed. The non-agglomerated particles decreased with the increase of specific surface of pellet feeds, showing that the increase of specific surface promote a better agglomeration behavior of the fines (Fig. 7(a)). The micropellets formation demonstrated a maximum for a specific surface around 1300-1 $500 \mathrm{~cm}^{2} / \mathrm{g}$ (Fig. 7(b)) whereas the quasi-particles formed reached a minimum, Fig. 7(c). However, the amount of quasi-particles formed remained the majority of the agglomerated particles. Based on these results, it was confirmed that the mechanism of formation of agglomerated particles was governed by quasi-
Table 7. Optical microscopy results of the quasi-particles.

\begin{tabular}{ccccc}
\hline Parameter & PF A & PF A.1 & PF B & PF B.1 \\
\hline \multicolumn{5}{c}{ Pellet feed specific surface } \\
\hline Characteristics of quasi-particles \\
\hline Index, $\mathrm{cm}^{2} / \mathrm{g}$ & 430 & 750 & 1470 & 2100 \\
\hline Thickness of aderent layer, mm & 0.115 & 0.149 & 0.137 & 0.185 \\
Circularity of quasi-particles & 0.660 & 0.657 & 0.657 & 0.660 \\
\hline \multicolumn{2}{c}{ Particle type formed, $\%$} & & \\
\hline Quasi-particles & 81.7 & 92.7 & 83 & 92.1 \\
Micropellets & 11.1 & 5.4 & 15.5 & 7.1 \\
Non-agglomerated & 7.2 & 1.9 & 1.5 & 0.8 \\
\hline Nucleus particles characterization, $\%$ & & \\
\hline Hematite & 13.7 & 13.4 & 13.5 & 23.3 \\
Goethite & 43.6 & 39.9 & 41.3 & 33.1 \\
Sinter return fines & 42 & 44.7 & 40.2 & 42.8 \\
Magnetite & 0.2 & 0 & 0 & 0 \\
Others & 0.5 & 2.1 & 5 & 0.8 \\
\hline
\end{tabular}

particles growing because of the deposition of ultrafines at the adherent layer (layering). Additionally, there was also a formation of micropellets with the ultrafines (coalescence) up to around $1300-1500 \mathrm{~cm}^{2} / \mathrm{g}$, but in a lower scale. This behavior explains the better granulation performance of the mixture up to this level of specific surface. On the other hand, values of specific surface higher than $1500 \mathrm{~cm}^{2} / \mathrm{g}$ indicate that the most important mechanism was the quasiparticles growing due to the deposition of ultrafines on the adherent layer (layering). This explains the agglomerated mean size of the quasi-particles and thickness of the adherent layer increasing with the increase of specific surface, but it not explains why the GI stabilized. Based on these findings it may be inferred that the thickness of adherent layer reaches a critical value for specific surfaces (around 1500 $\mathrm{cm}^{2} / \mathrm{g}$ ) and above that it became weak.

Once the most agglomerated particles formed were quasiparticles (Fig. 7) it is important to evaluate the nucleus particles characteristics, see Fig. 8. In general, an upward 


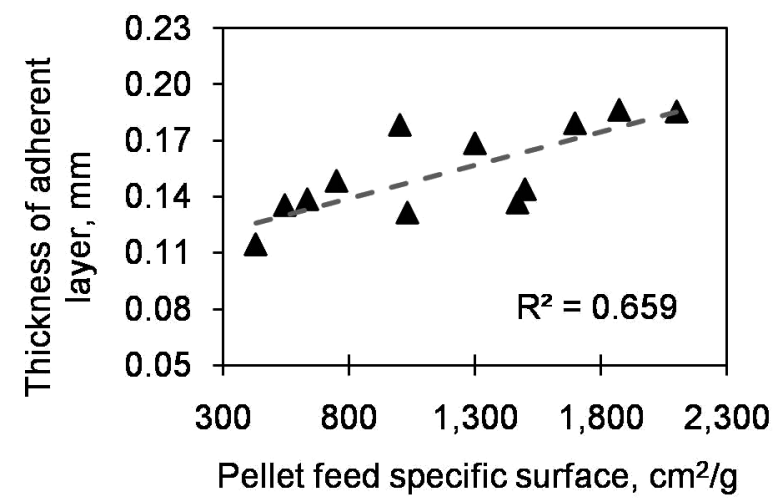

(a)

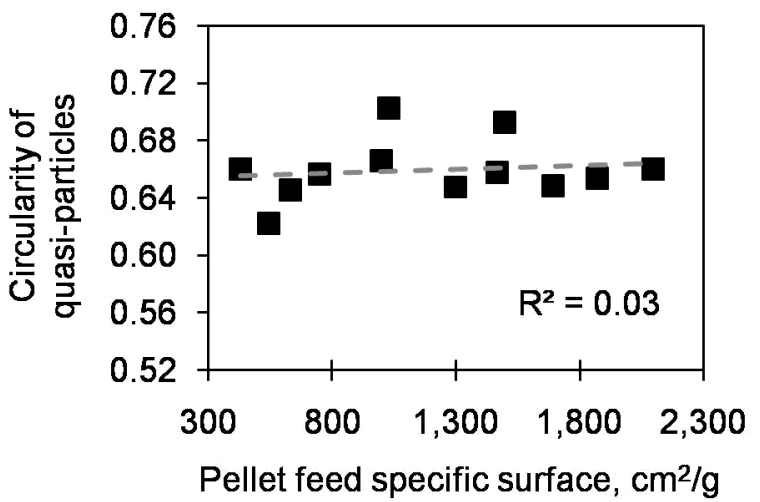

(b)

Fig. 6. (a) Thickness of adherent layer of the quasi-particles and specific surface of pellet feeds; and (b) Circularity of quasi-particles and specific surface of pellet feeds.

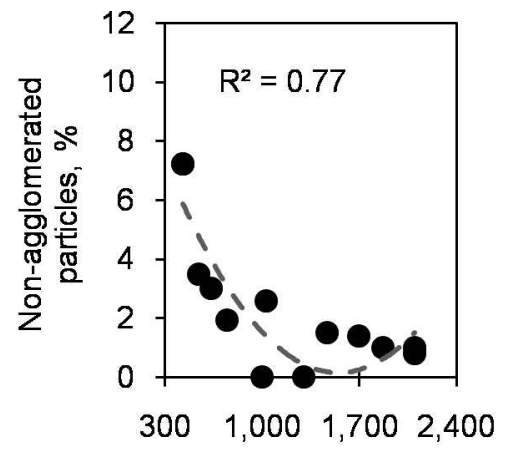

PF specific surface, $\mathrm{cm}^{2} / \mathrm{g}$

(a)

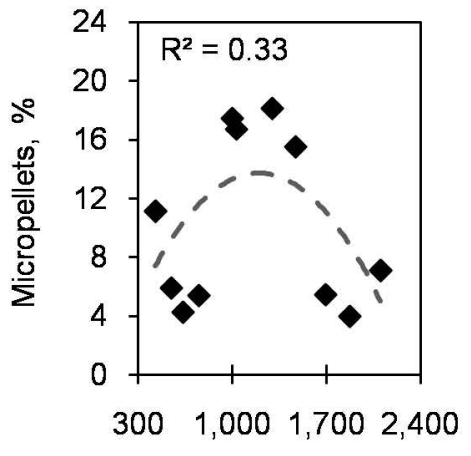

PF specific surface, $\mathrm{cm}^{2} / \mathrm{g}$

(b)

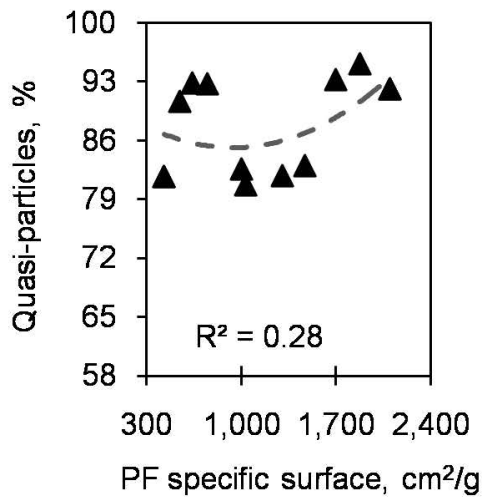

(c)

Fig. 7. Types of agglomerated particles with the specific surface of pellet feeds: (a) Non-agglomerated particles; (b) micropellets; and (c) quasi-particles.

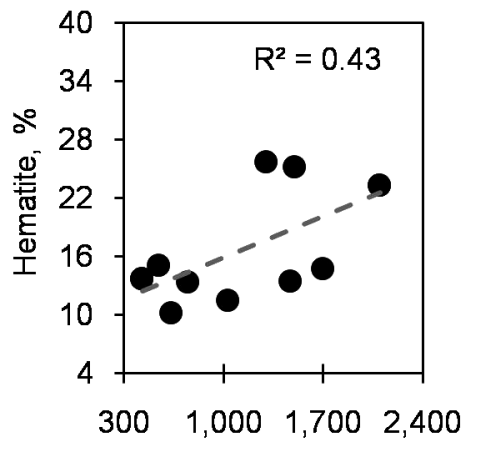

PF specific surface, $\mathrm{cm}^{2} / \mathrm{g}$

(a)

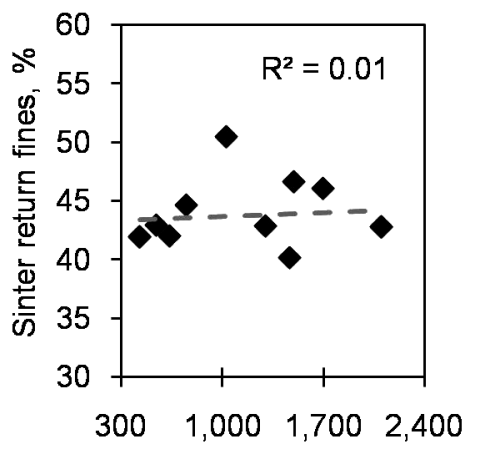

PF specific surface, $\mathrm{cm}^{2} / \mathrm{g}$

(b)

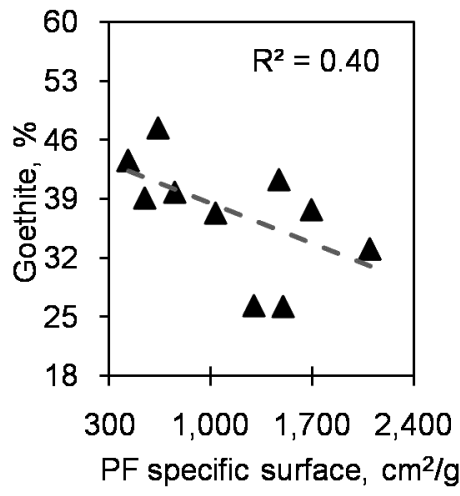

(c)

Fig. 8. Nucleus particles characteristics: (a) hematite; (b) sinter return fines; and (c) goethite.

increase of nucleus particles formed by hematite is observed when the specific surface increases, whereas the nucleus particles composed by goethite decrease. Normally, goethite ores are more porous, retaining more water in comparison to hematite ores, and require more water to have a good agglomeration behavior as reported in literature. ${ }^{4,6,24)}$ It means that these particles will compete with the fine particles of the pellet feed for the water available leading to decrease of nucleus particles formed by those ores. No clear trend was observed for the nucleus particles formed by the sinter return fines.

Detailed optical microscopy images of the quasi-particles were collected to compare the case with the lowest (PF A) and the highest (PF B.1) specific surface of pellet feed, Figs. 9(a) and 9(b), respectively. The pellet feed with the lowest specific surface lead to a low mean size of agglomerated particles, low thickness of adherent fines layer and low GI. This behavior is explained by the incomplete adherent layer 

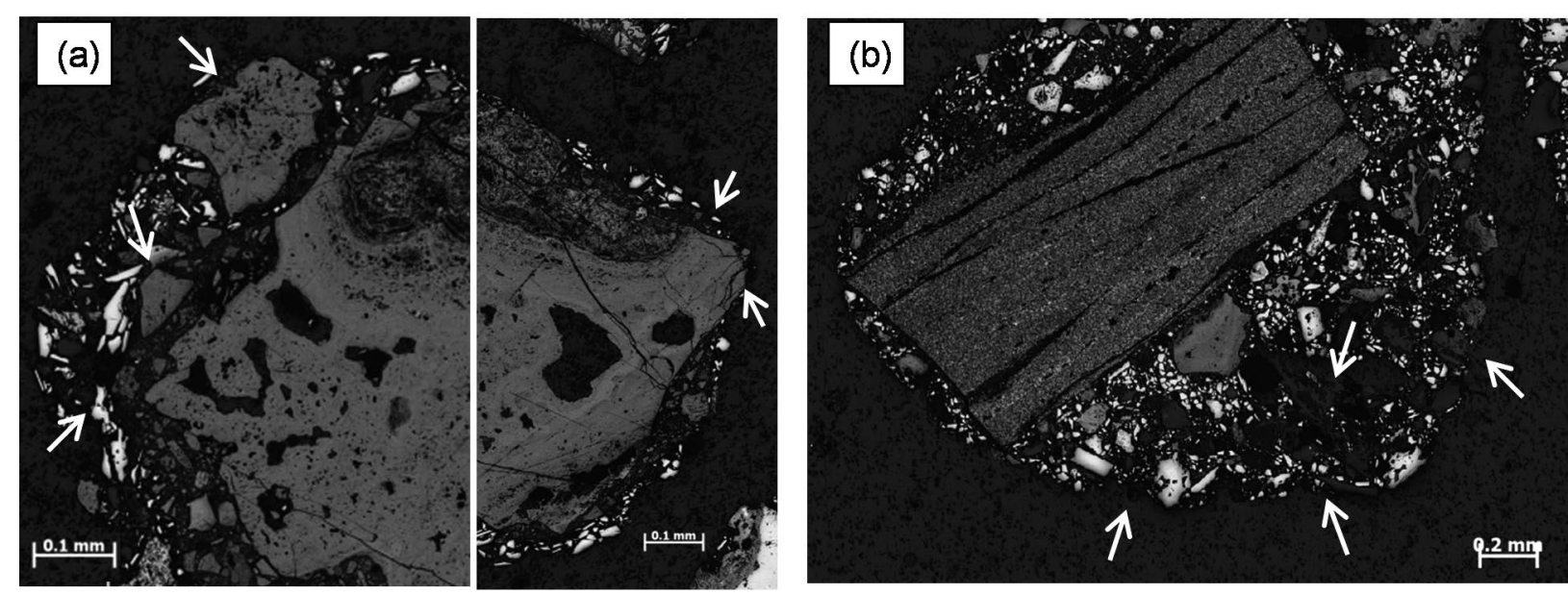

Fig. 9. Detailed images of the quasi-particles: (a) case with the lowest specific surface of pellet feed (PF A); and (b) case with the highest specific surface tested (PF B.1).

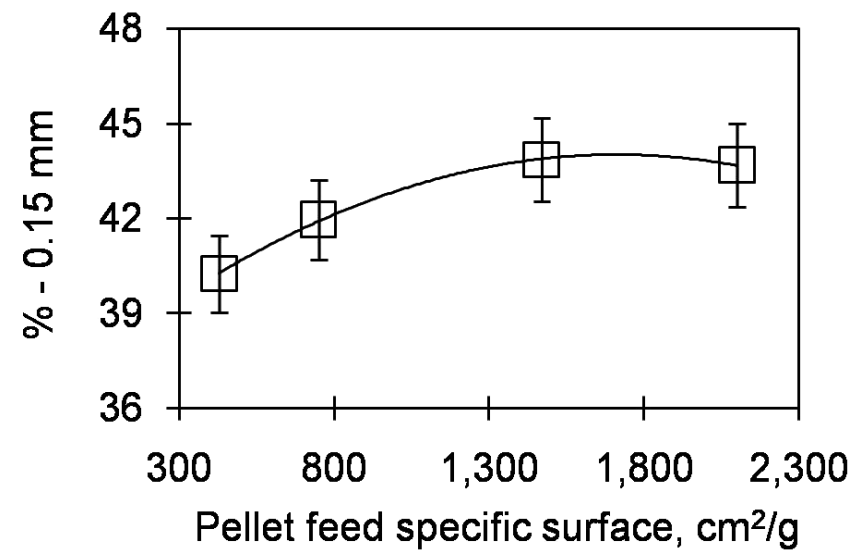

Fig. 10. Amount of fines below $0.15 \mathrm{~mm}$ that remain agglomerated after drop test as a function of the pellet feed specific surface.

formed, some voidages in this layer and coarse particles forming it, as indicated by arrows in Fig. 9(a). On the contrary, the pellet feed with the highest specific surface leads to high mean size of agglomerated particles, high thickness of adherent layer and good level of GI. This behavior may be explained by a good adherent layer formed with fine particles well distributed, but with some voidages (less than in the case with PF A) in this layer which contribute to the stabilization of GI for specific surface higher than $1400-1500 \mathrm{~cm}^{2} / \mathrm{g}$, as indicated by arrows in Fig. 9(b). Thus, a high thickness of the adherent layer does not mean a high GI or high strength of this layer.

In order to reinforce the hypothesis raised about the strength of the adherent layer of the quasi-particles, a drop test was carried out with the cases containing the pellet feeds A, A.1, B and B.1. Figure 10 shows that more fines below $0.15 \mathrm{~mm}$ remain agglomerated to quasi-particles or micropelletized with the increase of the specific surface up to $1400-1500 \mathrm{~cm}^{2} / \mathrm{g}$ and getting stable above these values.

The results presented in Fig. 10 are in line with the GI results confirming the hypothesis raised that for the pellet feeds of higher specific surface the quasi-particles grew (Fig. 9(b)), but they did not have enough strength to maintain its size. So, values higher than 1400-1 $500 \mathrm{~cm}^{2} / \mathrm{g}$ will not impact the permeability of the sintering process as its
GI and strength of quasi-particles stabilized, meaning that for the level of pellet feed tested, $25 \%$, it was the minimum value of specific surface needed for good sintering performance as confirmed through sintering pot test results reported by Oliveira et al. 2019. ${ }^{17)}$

\section{Conclusions}

The granulation phenomena involved during the preparation of iron ore mixtures for sintering played an important role in the process impacting directly the permeability of the bed and as consequence the productivity of sintering machine. In this context, an iron ore mixture containing $25 \%$ of pellet feed with different specific surfaces, i.e. natural, roller pressed and its fractions below $0.045 \mathrm{~mm}$, were evaluated and studied through bench scale granulation test. Based on the results achieved, the main conclusions are:

- The characterization of the pellet feeds used in this work showed that the fractions below $0.045 \mathrm{~mm}$ presents higher specific surface than the natural and pressed pellet feeds and higher ballability index, K. A complementary analysis obtained by SEM images showed the presence of small particles, cracks on the remaining larger particles and particles assuming a more rounded shape surface.

- The GI test results showed that the pressed pellet feed and its fraction below $0.045 \mathrm{~mm}$ presented higher values than the natural pellet feed and its fraction below $0.045 \mathrm{~mm}$. The mean size of agglomerated particles increased with the increase of specific surface of pellet feeds. The addition of the fractions below $0.045 \mathrm{~mm}$ of the pressed pellet feed to the natural sample improved the granulation behavior of the iron ore mixture.

- The GI results increase with the increase of pellet feed specific surface up to $1400-1500 \mathrm{~cm}^{2} / \mathrm{g}$. For values of specific surface higher than these values a stabilization of GI around $86-90 \%$ was observed. On the other hand, the mean size of the agglomerated particles formed after the granulation step increases continually with the pellet feed specific surface.

- Concerning the agglomerated particles, the thickness of adherent layer increases with the specific surface. About the particles type formed, the non-agglomerated particles decreased with the increase of the specific surface of pellet 
feeds, showing that the increase of specific surface promote a better agglomeration behavior of these fines. The quasiparticles formed remain most of the agglomerated particles.

- In general, an increasing trend of nucleus particles formed by hematite was observed with the increase of specific surfaces of pellet feed, whereas a decrease of nucleus particles formed by goethite was observed. No clear trend was observed for the nucleus particles formed by sinter return fines.

- The adherent layer formed with PF A (lowest specific surface) was incomplete with some voidages and coarse particles forming it. This explains the low mean size of agglomerated particles, low thickness of adherent fines layer and low GI. On the other hand, a good adherent layer formed with fine particles well distributed and less voidages was observed for the case with PF B.1 (the highest specific surface), which explains a high mean size of agglomerated particles, high thickness of adherent layer and good level of GI.

- Finally, the drop test carried out with the cases containing the pellet feeds and its fraction below $0.045 \mathrm{~mm}$ showed that the fines below $0.15 \mathrm{~mm}$ that remained agglomerated to quasi-particles or micropelletized increases with the increase of specific surface stabilizing for values higher than $1400-1500 \mathrm{~cm}^{2} / \mathrm{g}$, confirming the hypothesis that the quasi-particles strength also stabilizes.

\section{Acknowledgments}

The authors would like to thanks CAPES-PROEX, FAPEMIG and CNPQ, as well as all collaborators involved in the work at Vale S.A. and Federal University of Minas Gerais (UFMG).

\section{REFERENCES}

1) S. Wu, Z. Que and K. Li: J. Iron Steel Res. Int., 25 (2018), 1017. https://doi.org/10.1007/s42243-018-0153-9

2) C. Yang, D. Zhu, B. Shi, J. Pan, L. Lu, X. Li and Y. Mo: J. Iron Steel Res. Int., 24 (2017), 1007.

3) G. M. Walker: Handbook of Powder Technology - Granulation, 1st Ed., Vol. 11, ed. by A. D. Salman, M. J. Hounslow, J. P. K. Seville, Elsevier Science, Amsterdam, (2007), 219. https://doi.org/10.1016/ S0167-3785(07)80039-X

4) L. Lu and O. Ishiyama: Iron Ore - Mineralogy, Processing and Envi- ronmental Sustainability, 1st Ed., ed. by L. Lu, Elsevier, Amsterdam, (2015), 395. http://doi.org/10.1016/B978-1-78242-156-6.00014-9

5) C. B. Vieira, C. A. Rosière, E. Q. Pena, V. Seshadri and P. S. Assis: REM, Rev. Esc. Minas (Min. School's Magaz.), 56 (2003), 97 (in Portuguese). http://doi.org/10.1590/S0370-44672003000200006

6) J. Khosa and J. Manuel: ISIJ Int., 47 (2007), 965. https://doi. org/10.2355/isijinternational.47.965

7) Y. Ishikawa, K. Sugawara and Y. Umezu: Proc. 2nd Int Symp. on Agglomeration, AIME, Atlanta, (1977), 503.

8) K. Satoh: Flotation, 28 (1981), 99

9) D. Fernández-González, I. Ruiz-Bustinza, J. Mochón, C. GonzálezGasca and L. F. Verdeja: Miner. Process. Extr. Metall. Rev., 38 (2017), 36. https://doi.org/10.1080/08827508.2016.1244059

10) S. Wu, J. Zhu, J. Bei, G. Zhang and X. Zhai: Int. J. Miner. Metall. Mater., 22 (2015), 907. https://doi.org/10.1007/s12613-015-1149-0

11) T. Umadevi, A. Brahmacharyulu, A. K. Roy, P. C. Mahapatra, M. Prabhu and M. Ranjan: ISIJ Int., 51 (2011), 922. https://doi. org/10.2355/isijinternational.51.922

12) D. Zhu, J. Pan, L. Lu and R. J. Holmes: Iron Ore - Mineralogy, Processing and Environmental Sustainability, 1st Ed., ed. by L. Lu, Elsevier, Amsterdam, (2015), 435. https://doi.org/10.1016/B978-178242-156-6.00015-0

13) A. Abazarpoor, M. Halali, R. Hejazi and M. Saghaeian: Min. Process. Extract. Metall., 127 (2018), 40. http://doi.org/10.1080/03719553. 2017.1284414

14) D. Q. Zhu, J. Pan, T. J. Chun and D. Chen: Iron Ore Conf., AusIMM, Perth, (2011), 575.

15) P. Jian, Z. De-Qing, H. Pimenta, Z. Xian-Lin and W. Lin: ISIJ Int., 53, (2013), 2013. https://doi.org/10.2355/isijinternational.53.2013

16) M. Gan, X. H. Fan, Z. Y. Ji, X. L. Chen, L. Yin, T. Jiang, Z. Y. Yu and Y. S. Huang: Ironmaking Steelmaking, 42 (2015), 351. http://doi. org/10.1179/1743281214Y.0000000237

17) V. M. Oliveira, V. G. Resende, A. L. A. Domingues, M. C. Bagatini and L. F. A. Castro: J. Mater. Res. Technol., 8 (2019), 4985. https:// doi.org/10.1016/j.jmrt.2019.07.032

18) L. S. C. D'Avila, R. N. Azevedo, M. C. Bagatini and J. S. S. Castro: Proc. $45^{\circ}$ Ironmaking $/ 16^{\circ}$ Iron Ore $/ 3^{\circ}$ Agglomeration, (Rio De Janeiro), ABM, São Paulo, (2015), 921 (in Portuguese).

19) T. P. Silva, L. R. Lemos and L. F. A. Castro: Proc. $7^{\circ}$ Simpósio Brasileiro de Aglomeração de Minérios (7th Braz. Ore Agglom. Symp.), (São Paulo), ABM, São Paulo, (2019), 1 (in Portuguese). https://doi.org/10.5151/2594-357X-32526

20) A. F. L. Oliveira, R. A. L. Júnior, I. V. Flores, L. S. C. D’Avila and M. C. Bagatini: Proc. $7^{\circ}$ Simpósio Brasileiro de Aglomeração de Minérios (7th Braz. Ore Agglom. Symp.), (São Paulo), ABM, São Paulo, (2019), 316 (in Portuguese). https://doi.org/10.5151/2594$357 \mathrm{X}-33893$

21) V. Shatokha, I. Korobeynikov, E. Maire and J. Adrien: Ironmaking Steelmaking, 36 (2009), 416.

22) R. B. M. Santos, K. S. Augusto, S. Paciornik and A. L. A. Domingues: Min. Process. Extr. Metall., (2019), (Advance Publication). https://doi.org/10.1080/25726641.2019.1708656

23) H. Mao, R. Zhang, X. Lv, C. Bai and X. Huang: ISIJ Int., 53 (2013), 1491. https://doi.org/10.2355/isijinternational.53.1491

24) C. E. Loo: ISIJ Int., 45 (2005), 436. https://doi.org/10.2355/ isijinternational.45.436 